\title{
Brief
}

\section{Implantation of a left ventricular assist device and the hub-and-spoke system in treating acute cardiogenic shock: Who survives?}

Aftab R. Kherani, MD, Faisal H. Cheema, MD, Mehmet C. Oz, MD, Jennifer M. Fal, BA, Jeffrey A. Morgan, MD, Veli K. Topkara, David A. Wilson, BA, Deon W. Vigilance, MD, Mauricio J. Garrido, MD, and Yoshifumi Naka, MD, PhD, New York, NY

\footnotetext{
From the Columbia University, College of Physicians and Surgeons, Division of Cardiothoracic Surgery, New York, NY.

Received for publication Feb 14, 2003; accepted for publication April 1, 2003.

Address for reprints: Dr Y. Naka, New York Presbyterian Hospital, ColumbiaPresbyterian Center, Division of Cardiothoracic Surgery, Millstein Hospital Bld 7-435, 177 Fort Washington Ave, New York, NY 10032 (E-mail: yn22@ columbia.edu).

J Thorac Cardiovasc Surg 2003;126:1634-5

Copyright (C) 2003 by The American Association for Thoracic Surgery

$0022-5223 / 2003 \$ 30.00+0$

doi:10.1016/S0022-5223(03)00727-X
}

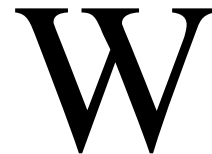

e have established a regional referral network that facilitates the transfer of patients in cardiogenic shock to our center for definitive management. This "hub-and-spoke" network has proven to be effective in treating this critically ill population. Postcardiotomy shock complicates $2 \%$ to $6 \%$ of cardiac procedures. ${ }^{1}$ The incidence of cardiogenic shock following acute myocardial infarction (AMI) is $5 \%$ to $15 \% .^{2}$ Medical management composed of inotropes and pressors with or without intra-aortic balloon pump support represents the standard of care in treating these patients. The advent of left ventricular assist devices (LVADs) introduced a surgical option for cases refractory to medical management. This study delineates who survives in this population and how the postcardiotomy setting impacts device placement.

\section{Methods}

This was a retrospective review looking at the short-term outcome of the 46 patients transferred from 22 spoke institutions to 1 tertiary hub center between October 1993 and May 2002 who underwent implantable LVAD insertion at the hub. Patients were placed into 1 of 3 groups:

1. Group A: patients were status post-AMI and did not undergo surgical revascularization [coronary artery bypass grafting $(\mathrm{CABG})]$ but instead were managed medically. Two patients additionally underwent extracorporeal ventricular assist device implantation at the spoke hospital (1 LVAD, 1 biventricular assist device).

2. Group B: patients were status post-AMI, had cardiogenic shock, and underwent emergency surgical revascularization at the spoke hospital prior to transfer.

3. Group C: patients had postcardiotomy shock after an elective cardiac procedure at the spoke facility.

Groups B and C distinguish themselves from A in that the former underwent traditional cardiac procedures on cardiopulmonary bypass at spoke hospitals either resulting in postcardiotomy shock or in an effort to treat it.

All statistical analysis employed SPSS version 10.0.1 (Chicago, Ill).

\section{Results}

The mean age of the 46 patients (33 men, 13 women) was $54.2 \pm 10.1$ years (range 17.8-66.4). There were 9 patients in group A, 18 in group B, and 19 in group C. The mean age of group A was $58.3 \pm 7.0$, in group B was $49.3 \pm 9.5$, and in group C was $56.8 \pm 10.5$ (ANOVA $P=.03$ ). At the time of arrival to the hub, markers of end-organ function (creatinine and prothrombin time) were comparable between the groups (Table 1).

Overall survival to discharge was $56.5 \%$ (26/46). Group A enjoyed a survival advantage over group $\mathrm{C}(P=.039)$. When group $\mathrm{A}$ was compared with groups $\mathrm{B}$ and $\mathrm{C}$ combined, statistical significance was nearly achieved $(P=.057)$. Table 1 summarizes.

Kaplan-Meier survival (Figure 1) revealed no significant differences between the groups (log-rank $P$ value: .23), although the trend did appear to favor group A. Three patients were successfully weaned off LVAD support; another 20 underwent transplantation. 


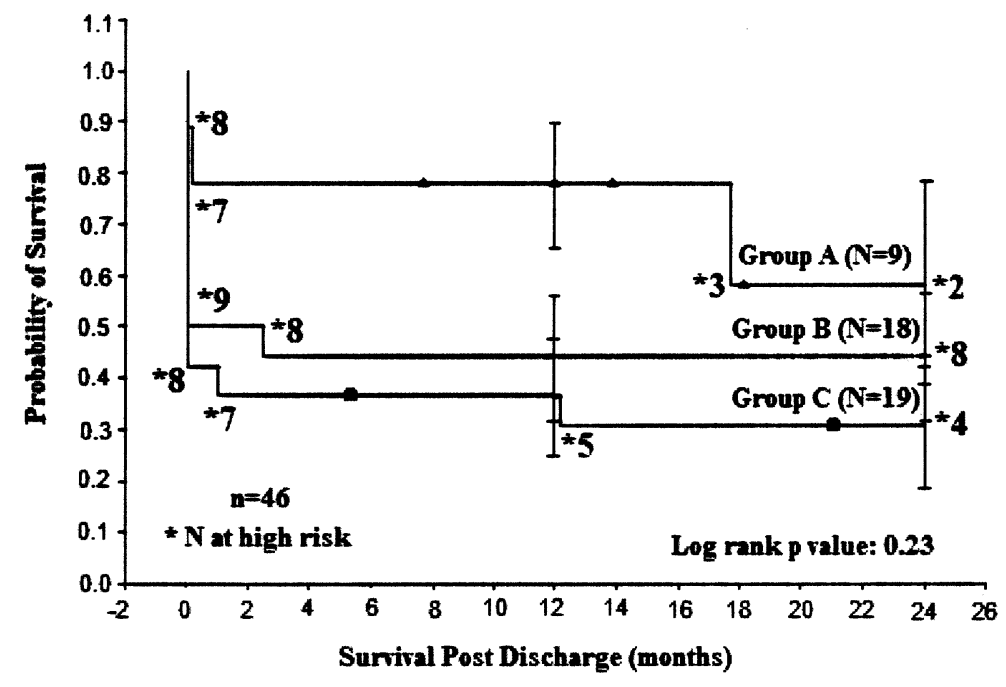

Figure 1. Hub-and-spoke (long-term implantable ventricular assist device). Kaplan-Meier survival of the 3 populations.

TABLE 1. Survival to discharge and markers of end-organ function in the three populations

\begin{tabular}{|c|c|c|c|c|c|c|c|}
\hline & Group A & Group B & Group C & $\begin{array}{c}\text { Group A vs } \\
\text { group B } \\
\text { ( } P \text { value) }\end{array}$ & $\begin{array}{c}\text { Group } A \text { vs } \\
\text { group } C \\
\text { ( } P \text { value })\end{array}$ & $\begin{array}{c}\text { Group B vs } \\
\text { group C } \\
\text { ( } P \text { value })\end{array}$ & $\begin{array}{c}\text { Group A vs } \\
\text { group B \& C } \\
\text { ( } P \text { value })\end{array}$ \\
\hline Survival to discharge & $8 / 9(88.8 \%)$ & $10 / 18(55.5 \%)$ & $8 / 19(42.1 \%)$ & .19 & .039 & .52 & .057 \\
\hline $\begin{array}{l}\text { Creatinine on arrival } \\
\text { at hub (mg/dL) }\end{array}$ & $1.9 \pm 0.9$ & $2.0 \pm 1.4$ & $2.0 \pm 1.7$ & .81 & .76 & .93 & .74 \\
\hline $\begin{array}{l}\text { Prothrombin time on } \\
\text { arrival at hub (s) }\end{array}$ & $19.1 \pm 5.1$ & $18.9 \pm 6.2$ & $28.7 \pm 37.0$ & .77 & .28 & .25 & .33 \\
\hline
\end{tabular}

\section{Discussion}

Cardiogenic shock is the leading cause of death in patients having an AMI. The majority of these patients $(71.7 \%)$ die in the hospital; in the absence of shock, mortality is significantly lower $(12.0 \%, P$ $<.001)^{2}$ The randomized SHOCK (Should We Emergently Revascularize Occluded Coronaries for Cardiogenic Shock) trial compared early revascularization (CABG or angioplasty) in patients with cardiogenic shock with medical management. Emergency revascularization did not significantly reduce mortality at 30 days, but after 6 months, a significant survival benefit was observed in these patients. ${ }^{3}$

Postcardiotomy shock similarly is associated with a poor prognosis, with only a quarter of all patients surviving to discharge. Ventricular assist devices have demonstrated effectiveness in treating these patients, and to this end, hub-and-spoke networks play an important role. Survival to discharge in our population was over $50 \%$.

These patient groups (A, B, and $\mathrm{C}$ ) are unique; thus, we understand that we are comparing "apples and oranges" to some extent and that our results speak only for the short-term. Yet even in this small, retrospective study, avoidance of non-LVAD surgical intervention at the spoke hospital generally improved survival to discharge, suggesting that the postcardiotomy setting may compromise subsequent ventricular assist device implantation. Thus, we advocate a larger-scale, prospective, randomized trial comparing ventricular assist device intervention with traditional revascularization in treating acute cardiogenic shock to clarify the potentially important role of ventricular assist devices in treating this population. Cost should be 1 factor examined to address how cost-effective maximal intervention is at treating these critically ill patients.

\section{References}

1. Helman DN, Morales DLS, Edwards NM, et al. Left ventricular assist device bridge-to-transplant network improves survival after failed cardiotomy. Ann Thorac Surg. 1999;68:1187-94.

2. Goldberg JR, Samad N, Yarzebski J, Gurwitz J, Bigelow C, Gore A. Temporal trends in cardiogenic shock complicating acute myocardial infarction. $N$ Engl J Med. 1999;340:1162-8.

3. Hochman JS, Sleeper LA, Webb JG, et al. Early revascularization in acute myocardial infarction complicated by cardiogenic shock. SHOCK Investigators. Should We Emergently Revascularize Occluded Coronaries for Cardiogenic Shock. N Engl J Med. 1999;341:625-34. 